\title{
Fairy Tale Situation Test for Implicit Theories of Personality
}

\author{
Yichen Cui ${ }^{1,2,}$, Zengkui Wan ${ }^{1,3}$, Qi Xia ${ }^{4}$, Yonghui Feng ${ }^{5}$, Wentai Gu$^{3}$, Lu Yang ${ }^{3}$, \\ Zhenzhong Zhou ${ }^{1,3}$ \\ ${ }^{1}$ Nanjing Institute of Juvenile Mental Health, Nanjing Xiaozhuang University, Nanjing, China \\ ${ }^{2}$ School of Social and Behavioral Sciences, Nanjing University, Nanjing, China \\ ${ }^{3}$ Institute of Mental Health, Nanjing Xiaozhuang University, Nanjing, China \\ ${ }^{4}$ Department of Architectural and Environmental Engineering, Yangzhou Technical Vocational College, Yangzhou, China \\ ${ }^{5}$ School of Educational Science, Hunan Normal University, Changsha, China
}

\section{Email address:}

zzcui@njfu.edu.cn (Yichen Cui)

*Corresponding author

\section{To cite this article:}

Yichen Cui, Zengkui Wan, Qi Xia, Yonghui Feng, Wentai Gu, Lu Yang, Zhenzhong Zhou. Fairy Tale Situation Test for Implicit Theories of Personality. American Journal of Applied Psychology. Vol. 9, No. 6, 2020, pp. 172-181. doi: 10.11648/j.ajap.20200906.15

Received: December 9, 2020; Accepted: January 11, 2021; Published: January 22, 2021

\begin{abstract}
When judging others, individuals often unconsciously apply their own special knowledge and personal constructs about human beings, which eventually forms some implicit theories of personality (ITPs). On the basis of different implicit personality theories, these individuals thus divided into two categories: a type of people believe that personality attributes or traits are sequestration, namely entity theorists; another type of people believe that personality attributes or characteristics are gradient, i.e. incremental theorists. Unlike studies that focus on how personality traits interact, implicit personality theory explores people's beliefs about the fixity and plasticity of personality traits. Based on projective techniques, a fairy tale situation test is developed to explore whether the implicit personality theories of college students have consistency across different personal attributes (such as characteristic or ability), as well as whether entity theory and incremental theory are two dimensions or two poles of the same dimension. The result of the pretest shows that the compiled fairy tale situation test could be a measurement to analyse the universality of implicit personality theory and the structural pattern of its dimension. A formal test separated the implicit personality theories of 120 college students. The results of both the pretest and the formal test indicated that (a) college students had a common and consistent implicit theory across five personal attributes including character, ability, temperament, morality, and emotion and that (b) entity theory and incremental theory were two inverse poles of the same dimension in implicit theories of personality. These results show that Implicit Theories of Personality has the characteristics of two dimensions (entity theory vs. gradient theory).
\end{abstract}

Keywords: Implicit Theories of Personality, Entity Theory, Incremental Theory, Projective Test, Fairy Tale Situation Test

\section{Introduction}

It is generally accepted that individuals apply their own specific knowledge about people in the process of judging others. The judging process is based on knowledge accumulated imperceptibly and organized in the practice of observing people, which is defined as the implicit theories of personality (ITP) [1], instead of through conscious inferences $[2,3]$. ITP is a basic cognitive pattern or a naive theory about human attributes including intelligence, morality, and personality incorporated by lay persons in interpersonal communication $[4,5]$.

\section{Literature Review and Method}

ITP manipulates and regulates people's understandings and reactions to their own behaviors and to the behaviors of others, thus causing different social cognitive patterns and behaviour reaction modes [6, 7]. ITP helps individuals generate a stable and meaningful behavioural tendency, which will be concretised in specific psychological situations [8]. Individuals usually incorporate one of two implicit theories of personality in their personal constructs. 
Individuals with an entity theory regard personality properties or traits as invariant [9, 10]. They tend to understand people's behavior by abstract, generalized and static internal qualities and they believe that human behavior is determined by these internal traits and rarely influenced by various internal and external factors. In contrast, individuals who are called incremental theorist with an incremental theory regard personality properties and traits as changing gradually across situations and time. They believe that people are individuals in the specific context and the characteristics of people are plastic and developmental. So, they think that people's behavior is influenced by various internal and external concrete background factors.

In recent years, researchers of personality psychology and social psychology usually discuss the ITP of "entity incremental theory dimension". This study has become a focus of research and trends $[7,10]$. Researchers believe that Belief System encourages people to produce causal attribution, and the Belief System is derived from the ITP [9, 10]. Leith et al. (2014) studied the relationship between ITP and attribution based on the attribution model of Gilbert (1988) [11]. According to the attribution model of Gilbert, the attribution of the individual to others is completed in 3 phases. These three stages are: The classification of behavior (categorization) (e.g., the behavior of "John got A" may be classified as "smart"), the characterization about the qualities of behavior (e.g., "John is wise."), correction of the previous trait reasoning by situational information (e.g., "test may be simple, so John is may not smart"). Leith et al. (2014) found that the first phase of behavior attribution isn't effected by ITP [11]. But compared with the entity theorists, incremental theory can make more interpretations of behavior based on limited situational information, and constantly correct the original attribution on the second and third phases. But entity theorists attribute personality traits to other people's behaviors. So, different implicit theories of personality lead to different attribution tendencies.

In real life, when individual meets the percept with specific identity or role, they always make processing strategy of person impressions affected by ITP. ITP affects how the percept extract others information directly. Because the entity theorists extract idiosyncratic information quickly via intuition and they extract behavior information via memory. Compared with incremental theorists, the entity theorists encode external information in the form of valuation. For example, they always give information labeled as positive or negative. The entity use ordinary, integral, rigescent processing strategy to make person impression and obtain conclusion. This process helps spontaneous trait inferences [3, 11]. Spontaneous trait inferences refer to the observer inference the process of personality traits and the formation of impressions by the lack of definite goals [12]. Researches show that entity theorists activate spontaneously the concept of quality in encoding on the behavior of a sentence compared with the incremental theory, so as to make more spontaneous trait inference [13]. For example, a student will be considered "violent" when he hit someone in school. And a staff will be considered "competent" when he (she) performs excellently in a task, etc.

In the views of these findings, researchers began to think about the question that whether the ITP have the effect of couping inter and exter and influence the processing way of person impressions for individual on the condition that ITP is looked as a kind of mental representation [7, 14]. As a result, some researchers take ITP as a coupling network between self-concept and personality characteristics, and individuals, groups and properties of characterization are stored in the connection in link libraries. In the link libraries $[15,16]$, ITP is drived by different personality characteristics and activate different self-concepts, which is self-perception in psychology. So the ITP can show the corresponding thinking and behavior habits temporarily. Apparently, this explanation reacts the flexibility and accommodative of processing strategy of person impressions [17].

ITP involves different personality attributes or fields with a focus on exploring how it applies to person perception, impression formation, and judgement as an important individual difference $[18,19]$. At present, researches mainly focus on personality traits, ability, morality, emotion, negotiation and so on [20, 21]. Romero et al. (2014) asked college students to explain specific behavioural events (e.g., "Alexis stole a loaf of bread at the bakery.") [22]. They found that entity theorists attempt to understand individuals' behaviors with abstract, broad, generalized, and static inner traits (e.g., "Alexis is a thief.", "Alexis is dishonest."), whereas incremental theorists understand behaviours by using specific internal and external factors that affect the dynamic psychological process (e.g., "Alexis is very hungry.", "Alexis is very desperate."). A study found that compared with the age of 16-22 teen who think their own capacity is changeless; some teens who think their own capacity have plasticity show less behavior problems and depression when they suffer from exclusion and abuse. At the same time, the incremental theorist show more positive and pro-social behaviors when in psychological intervention [23]. So Different ITP in ability or intelligence results in different reaction towards one's own failure. Researchers have also explored ITP in other fields. For instance, Hoyt and Burnette (2013) proposed implicit negotiation theories and discussed the influence of belief in negotiation ability stability on negotiation behaviour [24].

Are the implicit theories of personality universal? Can the implicit theories of personality remain coincident across different personal attributes and behavioural events? Two opposite views address the universality of ITP: In the first view, people have a general implicit personality theory and they always are consistent in their character, and ability. This assumption is proposed and verified by the self-report inventory and the effectiveness of the assumption remains to be further verified. Spinath et al. (2003) developed a scale for implicitpersonality, and special ability [25]. These results indicated that an individual's ITP on one attribute could largely predict the ITP on another attribute and 
agreed with the universal view of ITP. In the second view, there is no general ITP. One individual could be an entity theorist in some fields but become an incremental theorist in other fields. In another opinion about implicit negotiation theory, it is believed that an individual's belief in character does not transform into negotiating ability [26], in which empirical research has not developed systematically owing to limited methods. Together, the most important problem about the ITP appears to be the early self -report scale control.

The past research mostly used self-report personality inventory to measure the dimensions of ITP $[27,28]$. Some researchers also used indirect measurement method. The participants were asked to describe the different life style, to read stories and then be evaluated the characters in the story so their own personal construct can be projected in the story of the characters. We can distinguish entity and incremental theorists by this process [29]. The clinical study showed Fairy Tale Test (FTT) which is compiled by Coulacoglou (1992) on fairy tale proved that fairy tales can be a projection tool for personality assessment [30]. Compared with self-report personality inventory, FTT is likely to make participants focus on tasks, thus reducing the report of defensiveness [31]. The test form can make the "projection" touch the deep psychological personality, to avoid the Participants' perceptual bias and operant conditioning in a certain extent under the open, fuzzy, diverse background information (connecting characters of fairy tales with themselves or the characters in real life). In addition, people with different personalities have difference in the linguistic representation. This differential effects of individual psychological state which is showed by the structure of language differences is the clue that people observe and interpret the same differential, rich psychological world clues [32]. However, this projection test has not yet been extended and the external validity of the test is not high. The test time is relatively long and the scoring rules are not systematic. We need to provide a scoring system which is more quantitative, easy to operate and can be used by many people. At present, we can not make sure which kind of method is the best. Because the main measurement method is still a personality questionnaire and the indirect measurement paradigm in the detection of "hidden" personality has not received enough attention. Although the effectiveness of the former is verified to a certain extent $[6,33]$, it will not be as the best analysis paradigm of ITP $[20,34]$.

Some researchers argued that the conclusion should be cautiously made because of several weaknesses of the self-report personality scales. Firstly, the self-report method is based on the assumption that an individual is fully aware of his or her own ITP. This assumption is hardly satisfied because of the "implicit" nature of ITP [35]. Secondly, concealment of one's real reactions for socially desirable reasons is easy. More evidence is needed on the unidimensional or bidimensional nature of the entity-incremental nature of ITP. Thus, the key aspect is to focus on the implicitness of personality theory and to rethink and position researching methods. Projective technology is sensitive to the implicit cognition and can measure in multidimensions [36].

In the current study, we used projective technology to explore the universality and the dimensions of implicit theories of personality crossing different personality attributes. Fairy tales were chosen as the materials for this verbal projective test. There are mainly two reasons for choosing this material. Firstly, the information provided by fairy tales is both obscure and diverse, covering much different personality attributes and effectively establishing the entity-incremental distinction of ITP. Secondly, it is possible to design some fairy tale situations with no certain structure or fixed meaning. Research shows that how different the background of countries is. The fairy tale story can be designed without certain structure and fixed contexts to let the subjects free reaction for personality analysis [37]. Therefore, if the participants is in an imaginary space, the fairy tale situation and the inner world can map each other. Then the hidden implicit personality views will be unconsciously projected. Specifically, entity theorists project behavior of others according to the characteristics, so they will think the characters in fairy tales are stable and have characteristics of tendency to the behavior understanding, reasoning and prediction. While the incremental theorists believe that human trait is changing, and they attribute the behavior of fairy tale character to unstable factors and expected that the behavior will not occur again or predict hardly whether it appears again $[35,37]$.

In addition, we used college students as participants because they are in a special stage of personality and cognitive structure development. Given that, this research Prepared Fairy Tale Situation Test (FTST) and chosed college students as subjects, which aimed to test that different personality attributes of universality and latitude on ITP. There are some specific research hypothesis: (1) FTST can be used to as measuring tool of ITP and collect information for analyzing the universality and the structure of the latitude pattern of ITP. (2) College students have a consistent implicit theory which trends an unidimensional pattern (entity theory vs. incremental theory) on personality, temperament, ability, character, and emotion. The opposite of incremental theory is entity theory.

\section{Pre-Study 1: Determination of Basic Personal Attributes}

Before the formal test, the reliability and validity extracted from fairy tales made up by self are tested through pre-survey. The first step, using cluster analysis to sum up the 5 basic personality attributes of College student, that is, personality, temperament, ability, character, emotion. The second step, designing two sets of causes and ending of fairy tale situation to complete the test. Each of the test consisted of 5 fairy tales. In order to exclude interference by the difference between the East and the West, the revised 
fairy tales are from several countries; the 5 leading roles of the fairy tales have the 5 basic personality attributes individually, requiring subjects make attribution and forecast of the protagonist's behavior according to the plot of each fairy tale.

\subsection{Participants of Pre-study 1}

The participants were 110 undergraduates (58 males and 52 females) of average age of 21.3 years (ranging from 18 to $25)$. The participants were randomly divided into two groups (Group 1: 65, of which 32 were female and Group 2: 45, of which 20 were female).

\subsection{Materials and Procedures of Pre-study 1}

We used the 122 adjectives in The Adjective Table of Chinese Personality Features (Wang \& Cui, 2005) as the preliminary items. The participants of Group 1 were required to rate each adjective on the importance in describing personality features by using a seven-point scale (ranging from 1 = "not important" to 7 = "very important"). Those adjectives scoring $\geq 5$ were selected (Table 1). The participants of Group 2 were asked to quickly divide these 36 adjectives into several categories within 10 minutes. The standard of classification and the size of the categories were determined by the participants.

Table 1. Descriptive statistics of the selected adjectives.

\begin{tabular}{|c|c|c|c|c|c|c|c|c|}
\hline Rank & Characteristic & $M \pm S D$ & Rank & Characteristic & $M \pm S D$ & Rank & Characteristic & $M \pm S D$ \\
\hline 1 & Outgoing & $6.48 \pm 0.75$ & 13 & Selfish & $5.63 \pm 1.00$ & 25 & Astute & $5.26 \pm 1.23$ \\
\hline 2 & Introversive & $6.35 \pm 0.69$ & 14 & Palter & $5.58 \pm 1.03$ & 26 & Far-sighted & $5.22 \pm 1.26$ \\
\hline 3 & Easy-going & $6.04 \pm 0.61$ & 15 & Active & $5.55 \pm 1.08$ & 27 & Resourceful & $5.21 \pm 1.29$ \\
\hline 4 & Optimistic & $5.92 \pm 0.88$ & 16 & Impatient & $5.54 \pm 1.06$ & 28 & Thoughtful & $5.18 \pm 1.34$ \\
\hline 5 & Shy & $5.87 \pm 0.94$ & 17 & Melancholy & $5.46 \pm 1.05$ & 29 & Fitly spoken & $5.16 \pm 1.37$ \\
\hline 6 & Irresolution & $5.84 \pm 0.93$ & 18 & Good-tempered & $5.43 \pm 1.04$ & 30 & Rakish & $5.14 \pm 1.41$ \\
\hline 7 & Lonely & $5.82 \pm 0.91$ & 19 & Sensitive & $5.41 \pm 1.07$ & 31 & August & $5.11 \pm 1.54$ \\
\hline 9 & Elegant & $5.76 \pm 0.90$ & 21 & Well-informed & $5.38 \pm 1.11$ & 33 & Subtle & $5.05 \pm 1.73$ \\
\hline 10 & Charming & $5.72 \pm 0.97$ & 22 & Yes-man & $5.36 \pm 1.13$ & 34 & Greedy & $5.03 \pm 1.85$ \\
\hline 11 & Generous & $5.70 \pm 0.99$ & 23 & Freeloader & $5.33 \pm 1.15$ & 35 & Vulgar & $5.01 \pm 1.96$ \\
\hline 12 & Honest & $5.68 \pm 0.98$ & 24 & Out from within & $5.27 \pm 1.17$ & 36 & Countrified & $5.00 \pm 2.01$ \\
\hline
\end{tabular}

\subsection{Results of Pre-study 1}

Multidimensional scaling (MDS), a method that visualises clusters or dimensions of several objects in a low-dimensional space based on the similarity between objects, was adopted [6]. It serves the functions of both cluster analysis and factor analysis. Because the observed values of the correlations between the adjectives are coded in categories, it is suitable to use Kruskal's formula in a nonmetric MDS to determine the basic evaluation factors.

For the results of Group 2, first, input the distance matrix of all adjectives. If two adjectives are in the same category, mark 0 at the intersection of these two words; otherwise, mark 1 . So, a $36 \times 36$ matrix with 0 as the diagonal element is formed. Then, superpose the distance matrix of the 45 subjects, calculate the average $d_{j k}$ of each matrix, and analyse them using the nonmetric MDS of SPSS10.0.

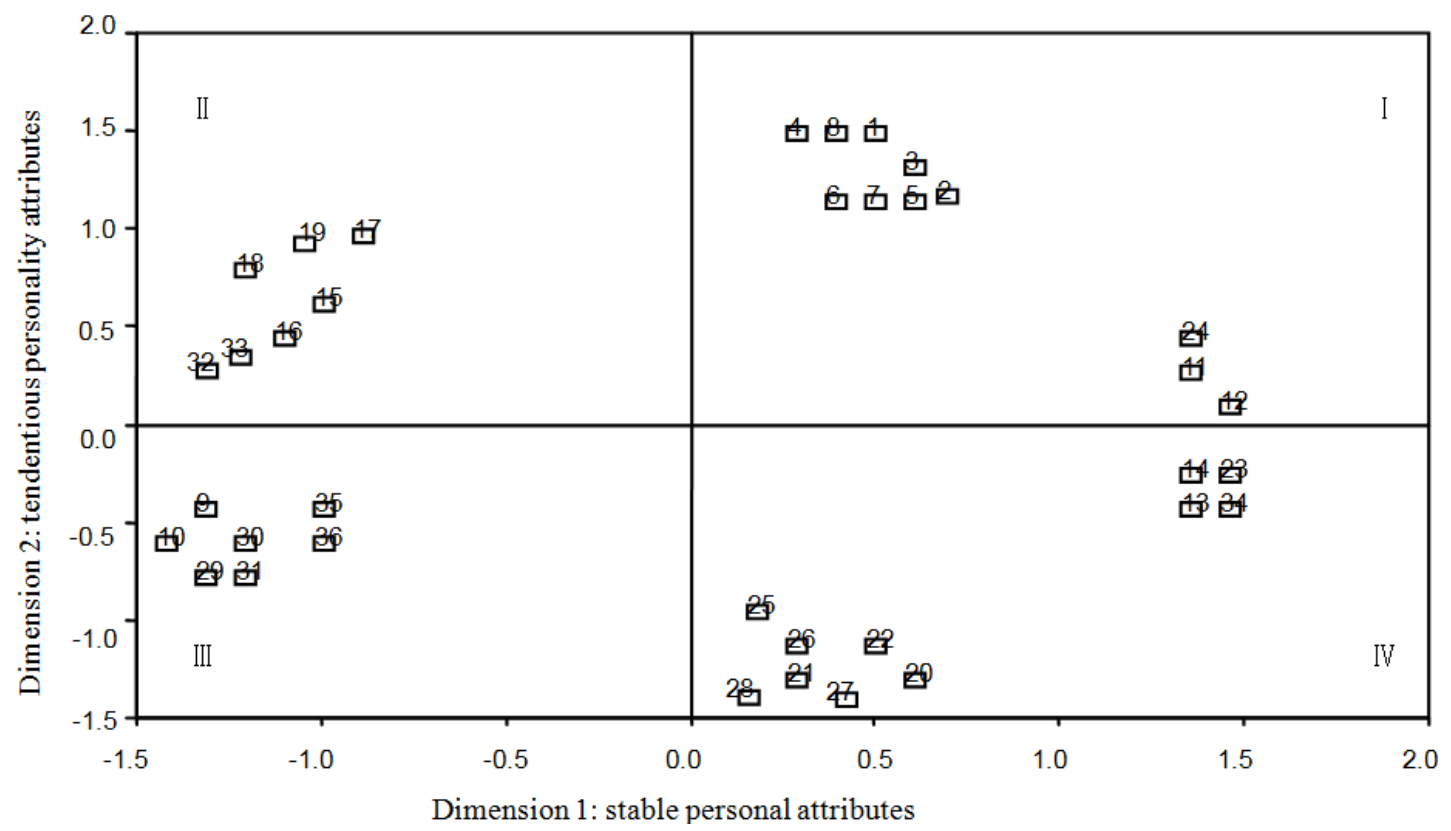

Figure 1. Two-dimensional clustering of 36 personality features. 
According to the results, the stress convergence value is 0.0001 and the minimum S-stress is 0.005 . The operation is iterated five times. It turns out that the goodness of fit of a two-dimensional (2D) model is better than that of a three-dimensional (3D) model (where, for the 2D model, stress $=0.056$ and RSQ $(\mathrm{r}$-squared $)=0.843$, and, for the $3 \mathrm{D}$ model, stress $=0.332$ and RSQ $=0.579$ ). The two dimensions in the graph are named according to the results of MDS analysis. They explained about $84 \%$ of the total variance of personal attributes. The numbers in the graph represent 36 personal attributes, respectively. These personality words in the two-dimensional coordinate space cluster into five categories. The categories are named and listed as follows: (1) character word (the first quadrant), (2) temperament words (the third quadrant), (3) ability words (the fourth quadrant), (4) moral character words (crossing the first and the four quadrant), and (5) emotional words (the second quadrant). According to the results, the implicit theories of personality could be measured through five categories of personal attributes: character, temperament, ability, moral, and emotion.

\section{Pre-study 2: Preliminary Test}

Those hypothesis: entity theorists believe that fairy tale characters act with stability, and they predict that similar behavior will happen again; incremental theorists believe that behavior of fairy tales are affected by the unstable factors, and they expect that similar behavior unlikely to happen again. Aided by the situation of fairy tales and based on the principle of projective test, this test is designed and later prediction is made. The purpose of Pre-study 2 is to collect materials for the fairy tale projective test and develop an initial version of the test. In the fairy tale projective test, it is assumed that entity theorists would explain the behaviors with stable factors and predict that the behaviors will occur again, whereas incremental theorists would explain the behaviors with unstable factors and predict more uncertainties in future behaviors.

\subsection{Participants of Pre-study 2}

The participants were 70 undergraduates ( 35 males and 35 females) of average age of 20.1 years (ranging from 17 to
25).

\subsection{Materials of Pre-study 2}

The materials used in the test were adapted from the fairy tales from China, Italy, Germany, Japan, India, and Burma. Each story involved one of the five personal attributes. The stories were somewhat structured yet ambiguous, thus allowing the participants to respond in many possible ways.

Two sets of stories were designed, and each set contains five stories targeting the five personality attributes $(86 \pm 4$ words for each story). For each story, the participants were required to freely explain the story and to predict the future behaviors of the characters in the story.

Forty undergraduates (20 males and 20 females of average age of 19.7) were recruited to analyse the content of the test. They were asked to categories each story into one of the five personality attributes. They were also asked to list the words that could describe the characters in the stories. Finally, the participants were asked to rate the stories regarding their familiarity with each story on a five-point scale (ranging from $1=$ "not familiar" to $5=$ "very familiar"). After inspection, the familiarity of fairy tale situation is below average low level $(M+S D=2.03+1.42)$.

There are the main contents of the analysis: (1) Deducing the hero dominant personality attributes (for example, we can conclude that the attribute of "ability" is advantage according to the "smart" and other words. And inferring the attribute of "good" is advantage acording to the "moral" and other words) according to the personality of character (counting the frequency percentage). (2) According to every plot of the tales, summed up the personality of hero (including animal and human, is "it", "he" or "she"), which requires the subjects according to their own understanding and write the answers (listed in the frequency feature the top three). And participants listed the feature words ranked in the top 3 . Test 1 and test 2 involving character, ability, moral character, temperament, emotion and every personality traits can be found only one corresponding point in each attribute of personality dimensions by table 3 . This make the measurement of ITP can be carried out under the dual dimension (entity theory - incremental theory). In addition, the familiarity about 10 fairy tales' situations of participants is low (Table 2).

Table 2. Results of the content analysis of the fairy tales.

\begin{tabular}{|c|c|c|c|c|c|c|c|c|}
\hline & \multirow{2}{*}{$\begin{array}{l}\text { Fairy } \\
\text { tale }\end{array}$} & \multirow{2}{*}{$\begin{array}{l}\text { Familiarity } \\
M \pm S D\end{array}$} & \multicolumn{5}{|l|}{ Theme (\%) } & \multirow{2}{*}{ Characteristics of the leading role } \\
\hline & & & Character & Temperament & Ability & Moral & Emotion & \\
\hline \multirow{5}{*}{ Set 1} & T1 & $1.87 \pm 1.35$ & 84.2 & 2.7 & 4.9 & 0 & 8.2 & Innocent, active, naughty \\
\hline & $\mathrm{T} 2$ & $1.92 \pm 1.28$ & 9.1 & 5.3 & 85.6 & 0 & 0 & Clever, erudite, whimsical \\
\hline & $\mathrm{T} 3$ & $1.84 \pm 2.61$ & 2.6 & 1.9 & 3.2 & 88.5 & 3.8 & Kind, obedient, determined \\
\hline & $\mathrm{T} 4$ & $1.93 \pm 1.21$ & 10.4 & 78.9 & 6.7 & 0 & 4.0 & Doubtful, oversensitive, forget oneself \\
\hline & T5 & $1.75 \pm 2.23$ & 3.3 & 2.6 & 0 & 2.4 & 91.7 & Distressed, moonstruck, negative \\
\hline \multirow{4}{*}{ Set 2} & T6 & $1.82 \pm 2.09$ & 84.0 & 6.1 & 0 & 6.3 & 3.6 & Lonely, Difficult to communicate, self-closing \\
\hline & $\mathrm{T} 8$ & $2.03 \pm 1.42$ & 4.3 & 3.9 & 0 & 89.6 & 2.2 & Grim, vicious, arrogant \\
\hline & T9 & $1.89 \pm 1.74$ & 6.3 & 79.5 & 0 & 0 & 14.2 & Vain, vulgar, shallow \\
\hline & $\mathrm{T} 10$ & $1.99 \pm 2.65$ & 1.7 & 3.8 & 12.6 & 5.2 & 76.7 & Caprice, changeable, elusive \\
\hline
\end{tabular}


they stood on the edge of the jar to dance, accidentally they fall into the inside. The jar was filled with sticky oil and they wanted to jump out. But the oil was too sticky and they and to got out of it, the wall was too slippery.

Most participants categorized the stories into the personality attributes as expected. For each story, the three words with the highest frequencies listed by the participants are listed in Table 2. The words in each story also matched the corresponding personality attributes. Familiarities with the ten fairy tales were all at a low level. The results showed that these stories were appropriate for the fairy tale situation test (Table 2).

\subsection{Scoring System}

The responses of the participants were coded. Table 3 details the operational definitions of the entity theory and the incremental theory and offers some response examples for character attribute. Within one sentence, either feature of the entity view or the incremental view could get 1 point for the corresponding view. Each feature could be scored only once. The features for the entity theory would be positively scored and those for the incremental theory would be negatively scored. The verbal strengths for each coded features were weighted.

Table 3. Comparison of the specific meaning of implicit view in character attributes.

\begin{tabular}{lll}
\hline Theory & Feature & Example \\
\hline \multirow{4}{*}{ Entity theory } & Characters are usually fixed. & The giant is still opinionated, selfish, eccentric, and isolated. \\
& Characters rarely are obtained through learning. & Two little frogs are still naughty, bold, and comfortable. \\
& Characters rarely are nurtured by environments. & The giant is usually a very stingy person. \\
& Efforts can hardly change characters. & The two frogs try many ways and ultimately give up. \\
& Characters usually can be changed. & The giant quickly wakes up to his error and invites children to play in the garden. \\
Incremental & Characters are usually obtained through learning. & Two little frogs learn a lesson and work hard in the field. \\
& Characters are often fostered by environments. & After the giant's wife died, he gradually became depressed in sorrow. \\
& Efforts may change characters. & The two frogs make concerted efforts and calmly think of a way to escape.
\end{tabular}

This table offers examples of the implicit view features for character. The implicit view features for ability, moral, temperament, and emotion are the same.

The original score from each participant was divided by the number of words in the article. The average correction scores of the 10 tests were calculated and were transformed into a $T$ fraction.

\subsection{Results of Pre-study 2}

\subsubsection{Reliability Test}

Inter-rater reliability Five psychology undergraduates (who were not involved in the test and who fully understood the scoring rules) independently coded the participants' responses. The Kendall coefficient among the raters was $W=$ $0.87\left(\chi^{2}=138.26, p<0.001\right)$.

Test-retest reliability The same test was readministered 2 weeks after the first test. The Pearson correlation was $r=$ $0.63(t=3.01, p=0.008)$.

Alternate-form reliability Two sets of tests were conducted 2 weeks apart. The Pearson correlation was $r=0.52(t=2.82$, $p=0.035)$, indicating that random errors were strictly controlled. Thus the cross-situation stability of ITP can be tested more effectively.

\subsubsection{Validity Test}

Construct validity We used the multitrait-multimethod matrix (MTMM) approach, which is used to test models of multiple traits tested by multiple methods [10], to analyze the structure validity of the test.

Multitrait refers to the attribute factor of ITP. Multimethod refers to the project factor in the measurement (i.e., the subtests with different content and forms). Each story in the test is attributed to one of the attribute factors and to one of the project factors.

The scores of different attributes in the same project are different, and the scores of the same attribute in different projects are also different (Table 4). This showed that the test results are affected not only by the implicit views but also by the method. The average correlation of the scores of same-trait-different-method was 0.86 , which was greater than that of different-trait-same-method $(r=0.17)$ or that of different-trait-different-method $(r=0.07)$. These results implied good convergent validity and discriminant validity of the test.

Table 4. MTMM of attribute factors and project factors.

\begin{tabular}{|c|c|c|c|c|c|c|c|c|c|c|c|}
\hline & & \multicolumn{5}{|l|}{ I1 } & \multicolumn{5}{|l|}{ I2 } \\
\hline & & A1 & $\mathbf{A 2}$ & $\mathbf{A 3}$ & A4 & A5 & A'1 & A'2 & A'3 & $A^{\prime} 4$ & A'5 \\
\hline \multirow{5}{*}{ I1 } & A1 & 0.67 & & & & & & & & & \\
\hline & A2 & 0.29 & 0.59 & & & & & & & & \\
\hline & A3 & 0.25 & 0.19 & 0.73 & & & & & & & \\
\hline & A4 & 0.22 & 0.13 & 0.11 & 0.58 & & & & & & \\
\hline & A5 & 0.26 & 0.09 & 0.12 & 0.33 & 0.54 & & & & & \\
\hline \multirow{5}{*}{$\mathrm{I} 2$} & $A^{\prime} 1$ & 0.89 & 0.07 & 0.09 & 0.08 & 0.09 & 0.64 & & & & \\
\hline & $\mathrm{A}^{\prime} 2$ & 0.08 & 0.91 & 0.04 & 0.05 & 0.06 & 0.07 & 0.66 & & & \\
\hline & $\mathrm{A}^{\prime} 3$ & 0.07 & 0.05 & 0.94 & 0.05 & 0.11 & 0.10 & 0.08 & 0.74 & & \\
\hline & $\mathrm{A}^{\prime} 4$ & 0.06 & 0.07 & 0.10 & 0.82 & 0.04 & 0.09 & 0.06 & 0.31 & 0.57 & \\
\hline & $A^{\prime} 5$ & 0.05 & 0.09 & 0.04 & 0.04 & 0.76 & 0.12 & 0.05 & 0.25 & 0.33 & 0.53 \\
\hline
\end{tabular}


(1) "A" indicates the attribute factor and "I" indicates the project factor. A1-A5, respectively, represent the implicit views of character, ability, moral, temperament, and emotion. I1 represents subtest 1 and I2 represents subtest 2. (2) The correlations within the two solid triangles are the correlations between scores of different-trait-same-method. The doted diagonal within the doted matrix indicates the correlations between scores of same-trait-different-method. The rest of the doted matrix indicates the correlations between scores of different-trait-different-method.

We further tested the construct validity of the test by using the structural equation model analysis with LISREL 8.30. We hypothesized these six alternative models:

Model 1: the null model. The observed variables are independent factors and the attribute factors are independent factors. The covariances between any two factors are expected to be zero. The error matrix is the diagonal matrix.

Model 2: the baseline model; 5 relevant attribute factors and 2 relevant project factors $(\mathrm{NK}=7)$. This model is the one with the least limiting factors among all models, so it can be a baseline model.

Model 3: 5 relevant attribute factors and 2 irrelevant project factors $(\mathrm{NK}=7)$. Attribute factors are set as free parameters and project factors are set as fixed parameters (0.0) $(\mathrm{PH}=\mathrm{SY}, \mathrm{FI})$.

Model 4: 5 related attribute factors and no project factor $(\mathrm{NK}=5)$. The load and error of attribute factors are just kept. The covariance matrix of factors is a symmetric fixed parameter matrix $(\mathrm{PH}=\mathrm{SY}, \mathrm{FI})$.

Model 5: 2 related project factors and no attribute factor $(\mathrm{NK}=2)$. The model just keeps the load and error of project factors. Covariance factors are set as free parameters.

Model 6: 5 fully relevant attribute factors and 2 free related project factors $(\mathrm{NK}=3)$. There is a general attribute factor. The covariance of attribute factors is a fixed parameter value (1.0) and the correlation of project factors is a free parameter estimation.

The fitting indexes of the six hypothesized models are listed in Table 5. Model 2 and Model 6 are better fitted compared with other models. Model 2 is more consistent with our original construct of the test, however, Model 6 performed better on the principle of parsimony (Widaman \& Thompson, 2003), and the RMSEA for Model 6 was also smaller. Thus it is reasonable to accept the model that there is one common implicit view across the five personal attributes (see Figure 2 for a diagram of Model 6).

Table 5. Confirmatory factor analysis results of different models.

\begin{tabular}{llllll}
\hline Model & $\chi^{2} /$ degrees of freedom & GFI & AGFI & CFI & RMSEA \\
\hline 1 & 6.581 & - & - & 0.902 & 0.876 \\
2 & 1.056 & 0.954 & 0.764 & 0.725 & 0.057 \\
3 & 1.203 & 0.816 & 0.672 & 0.631 & 0.062 \\
4 & 2.394 & 0.583 & 0.542 & 0.418 & 0.038 \\
5 & 2.135 & 0.933 & 0.889 & 0.026 \\
\hline
\end{tabular}

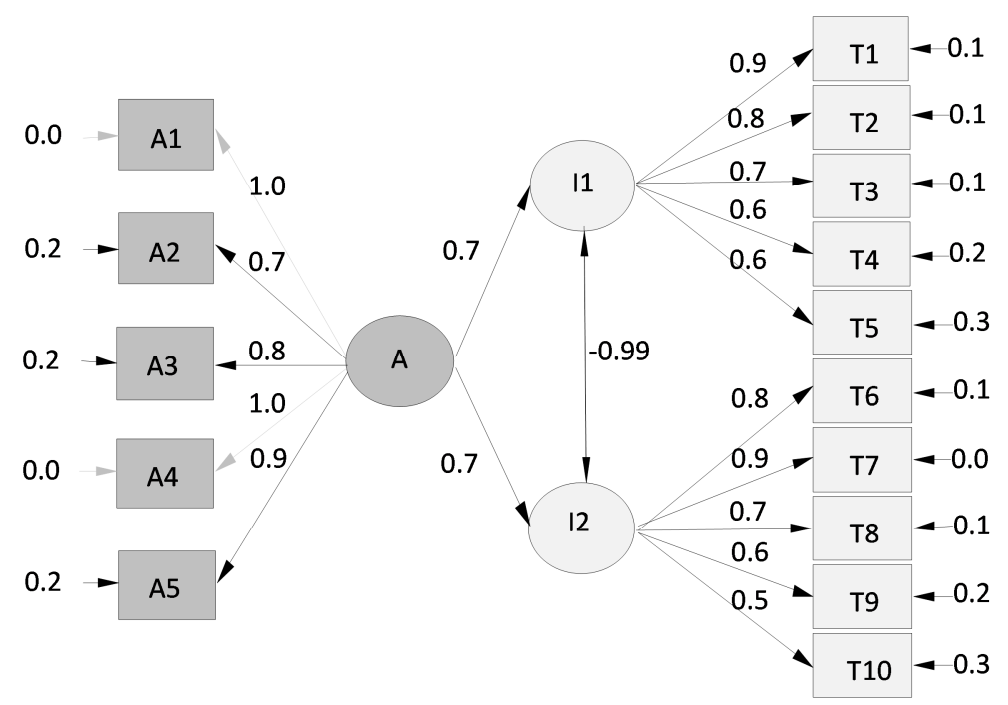

Figure 2. Covariance structure model of implicit theories of personality.

In this diagram, A, I1, and I2 are latent variables and they, respectively, represent the common implicit view and two subtests; A1-A5 and T1-T10 are the observed variables, which represent 5 kinds of personal attributes and 10 fairy tale situations.

Empirical validity We used the distinguish method to analyze the empirical validity of the test (Baig, Violato, \& Crutcher, 2010). Each participant was asked whether his or her performance in exams could be improved through effort. Their responses were selected as a criterion of this test. An independent-sample $t$ test showed that the participants who 
chose "yes" scored higher in the test $(M=72.51)$ than those who chose "no" $(M=57.69): t(68)=15.82, p<0.001$. This result shows that this test has a high empirical validity.

Fairy Tale Situation Test by reliability test and validity test conformed the measurement standards coincidence measurement standard, so it can enter the formal test stage. In addition, through the pre-survey of ITP, we further confirmed FTST can be seen as a projective test, and this test can make the participants attribute and predict the behaviors of fairy tale characters according to ITP. The pretest of FTST showed that it can test effectively the ITP held by the participants and provide a reliable basis for the formal test to analyze further the universality and dimension of ITP. So, the test can measure the real state of participants' ITP.

\section{Formal Test}

\subsection{Participants of Formal Test}

The participants were 68 undergraduates from Grade 2 and 4 (36 males an d 32 females) and 52 junior college students from Grade 1 and 3 ( 24 males and 28 females) of average age of 20.5 (ranging from 17 to 26), and their majors cover Chinese, Maths, History, Biology, Foreign Language, Physics, Education and Psychology. Additionally, they are all right-handed and have normal eyesight or corrected eyesight. Their hearings are also normal. And all the subjects have never taken part in quasi experiments. A little bonus will be provided after the experiment.

\subsection{Procedure of Formal Test}

The participants were asked to take a written examination within 60 minutes. The instructions were: "Please guess, how do the following contexts take place? That is to say, what's the reason for the happening of the story? What will the ending be like with the development?" The experimenter will emphasize at the same time: "Please make use of your imagination and write as detailed as possible." Considering the large amount of the participants, test will be conducted twice with the same environment, interference and instructions.

\subsection{Results of Formal Test}

Five college students independently scored the responses. The specific algorithm for feature points in scoring the features of each sentence is each one (see Table 3 ) scoring 1 point, no such feature scoring 0 points, and four features scoring 4 points (i.e., the same way as explained in Pre-study 2). Some features seem to have the entity or incremental features only from the surface and were given a weight of 0 . Consider the following scoring process as an example:

Entity theory

Reason: Two frogs lived so comfortably that they didn't experience any changes. Whatever they did, they did not consider consequences, as long as they were happy. They thought that the outside world is wonderful, so they get dizzy with success and eventually this led to bitter fruit.

Ending: The two frogs struggled hard in the jar, but the harder they struggled, the deeper they sank. Faced with difficulties, they chose to retreat, await their doom, and wait for death. They imperceptibly fell asleep. In the dream, they returned to the green paddy fields and there were their partners, their food, and the bright sunlight.

(Number of words: 174)

Score: Characteristic score $=3$, weight $=3$, original score $=6$, correction $=3.4$.

One-hundred and twenty college students participated in the fairy tale situation test; 42 entity subjects (correction $>0$, $T$ score $\geq 60$ ) and 48 incremental subjects (correction $<0, T$ score $\leq 40)^{1}$ were selected. It turns out that the fairy tale situation test can effectively distinguish an individual's implicit theories of personality. Incremental theory is opposite to entity theory and they were two poles of the same dimension; there existed common implicit theories across different personality attributes such as characteristic and ability.

\section{Discussion}

Compared with self-report personality inventories, fairy tale situation can attract more attention of individual and reduce the defense psychological and focus on the task. This test can make projection touch deep personality under the open, blurry, diversified background. So this test can avoid perceptual bias and operable conditioned reflex, which is connect fairy characters with themselves and real characters.

In addition, the people with different personality have some difference in language representation. This differential effect on individual psychological states through the difference of language construction is clue to observe and explain the different and abundant psychological world [27]. However, this projective test do not popularize. Because the external efficiency of the test is not high, the test time is too long and the scoring system is not systematize. So we need a more quantitative, handier and many people used scaring system.

According to Hoty and Burnette's research, implicit theories of different personalities are independent with each other, which indicates individual's implicit personalities are unlikely to be universal.

Previous tests of implicit theories of personality categorized implicit theories of personality within the same dimensionality $[29,30]$. For example, the personality will be classified into stable/malleable traits based on the score, making the hidden implicit personality express out unconsciously. This subjective method of classification stipulates unidimensional property of implicit personality firstly. Therefore, researchers cannot determine whether or not those tests support the sequestration view. Because of this, the fairy tale situation test the study adapt avoids single dimension hypothesis, excavating dimension characteristics

1Given that that the $T$ score threshold of entity theorists and incremental theorists is 50 , subjects whose $T$ scores were between 40 and 60 were rejected. 
of the implicit personality theories, and that makes the results more convincing. According to the statistical data, this study enables the use of single dimensional scale, which uses the same dimension to determine individual's implicit personality theories simultaneously. Character, ability, morality, temperament and mood are 5 personal attributes that belong to 5 fields that are quite different from each other. If these five attributes are not seen as a community with a stable structure, it will be hard to analyze whether implicit cross personality are universal. Of course, we have to do further research on this ratiocination.

This work is the first time in which a fairy tale situation test has been adopted in the empirical research of implicit personality theory. However, compiling the projective test was inspired by related research, not by accident. For example, to investigate the trait beliefs of children and adults, Lockhart et al. (2002) made up some stories, each relating to a trait. Each story describes behaviors of a child [32]. The trait is either a negative trait or a positive one. The participants were asked to predict to what extent the child's behavior would change at 21 . Their results showed that some individuals would take an intermediate view of trait variability in which some traits are variable while some are invariable. In addition, people with different personalities have differences in linguistic representations. This differential effect of the psychological state could be revealed by the different structures people used in describing and understanding fairy tales [6, 34-36]. Therefore, as subsequent development and application of the fairy tale situation test, we can explore the methodology of the compilation of the test and demonstrate the universality, dimension, and other issues of implicit personality theory in multiple ways from the perspective of application.

Previous tests categorised implicit theories of personality within the same dimensionality [34-36]. Therefore, researchers cannot determine whether those tests support the sequestration view. This study adopts a projective test to explore the universality and dimension of implicit theories of personality crossing different personality attributes. It compensates for the limits of the single dimension scale and confirms the hypothesis that implicit personality theory has a single dimension in a certain range of groups.

Nonetheless, this result needs further verification. Some research has shown that people's implicit personality theory is not consistent across all their personal attributes [37]. More research is needed to further confirm the cross-situational consistency of ITP. Furthermore, it is still necessary to further examine the validity and reliability of the fairy tale situation test in different samples.

\section{Conclusion}

Fairy Tale Situation Test is sensitive to implicit behaviour or subconscious processes of participants, and it can detect implicit theories of personality efficiently. With it, we found that (a) college students had a common and consistent implicit theory across five personal attributes including character, ability, temperament, morality, and emotion and that (b) entity theory and incremental theory were two inverse poles of the same dimension in implicit theories of personality. These results show that Implicit Theories of Personality has the characteristics of two dimensions (entity theory vs. gradient theory).

\section{References}

[1] Barsky, A. P., \& Zyphur, M. J. (2016). Disentangling sunk-costs and completion proximity: The role of regulatory focus. Journal of Experimental Social Psychology, 65, 105108. doi: 10.1016/j.jesp.2016.04.006.

[2] Burnette, J. L., O’Boyle, E. H., VanEpps, E. M., Pollack, J. M., \& Finkel, E. J. (2013). Mind-sets matter: A meta-analytic review of implicit theories and self-regulation. Psychological Bulletin, 139 (3), 655-701. doi: 10.1037/a0029531.

[3] Plaks, J, E., \& Halvorson, H. G. (2013). Does accountability attenuate or amplify stereotyping? The role of implicit theories. Social Cognition, 31 (5), 543-561. doi: 10.1521/soco.2013.31.5.543.

[4] Reinhard, M. A., Sporer, S. L., Scharmach, M., \& Marksteiner, T. (2011). Listening, not watching: Situational familiarity and the ability to detect deception. Journal of Personality and Social Psychology, 101, 467-484. doi: 10.1037/a0023726.

[5] Strack, F., \& Deutsch, R. (2011). A theory of impulse and reflection. In P. A. M. Van Lange, A. W. Kruglanski, \& E. T. Higgins (Eds.), Handbook of Theories of Social Psychology (pp. 97-117). London: Sage.

[6] Park, D., \& Kim, S. (2015). Time to move on? when entity theorists perform better than incremental theorists. Personality and Social Psychology Bulletin, 41, 736-748. doi: $10.1177 / 0146167215578028$

[7] Yeager, D. S., Lee, H. Y., \& Jamieson, J. P. (2016). How to improve adolescent stress responses: Insights from integrating implicit theories of personality and biopsychosocial models. Psychological Science, 27 (8), 1078-1091. doi: 10.1177/0956797616649604.

[8] Double, K. S., \& Birney, D. P. (2016). The effects of personality and metacognitive beliefs on cognitive training adherence and performance. Personality and Individual Differences, 102, 7-12. doi: 10.1016/j.paid.2016.04.101.

[9] Snyder, K. E., Malin, J. L., Dent, A. L., \& Linnenbrink-Garcia, L. (2014). The message matters: The role of implicit beliefs about giftedness and failure experiences in academic self-handicapping. Journal of Educational Psychology, 106, 230-241. doi: 10.1037/a0034553.

[10] Ziegler, A., Fidelman, M., Reutlinger, M., et al. (2010). Implicit personality theories on the modifiability and stability of the action repertoire as a meaningful framework for individual motivation: A cross-cultural study. High Ability Study, 21, 147-163. doi: 10.1080/13598139.2010.528924.

[11] Leith, S. A., Ward, C. L. P., Giacomin, M., Landau, E. S., Ehrlinger, J., \& Wilson, A. E. (2014). Changing theories of change: Strategic shifting in implicit theory endorsement. Journal of Personality and Social Psychology, 107 (4), 597620. doi: 10.1037/a0037699. 
[12] Yin, C. Y., Yu, H. Y., \& Poon, P. (2016). Consumers' attributions and brand evaluations in product-harm crises: The role of implicit theories of personality. Journal of Consumer Behaviour, 15, 87-95. doi: 10.1002/cb.1549.

[13] Rattan, A., \& Dweck, C. S. (2010). Who confronts prejudice? The role of implicit theories in the motivation to confront prejudice. Psychological Science, 21 (7), 952-959. doi: 10.1177/0956797610374740.

[14] Plaks, J. E., \& Chasteen, A. L. (2013). Entity versus incremental theories predict older adults' memory performance. Psychology and Aging, 28 (4), 948-957. doi: $10.1037 / \mathrm{a} 0034348$.

[15] Awh, E., Belopolsky, A. V., \& Theeuwes, J. (2012). Top-down versus bottom-up attentional control: A failed theoretical dichotomy. Trends in Cognitive Sciences, 16 (8), 437-443. doi: 10.1016/j.tics.2012.06.010.

[16] Baig, L., Violato, C., \& Crutcher, R. (2010). A construct validity study of clinical competence: A multitrait multimethod matrix approach. Journal of Continuing Education in the Health Professions, 30, 19-25. doi: doi.org/10.1002/chp.20052.

[17] Park, J. K., \& John, D. R. (2012). Capitalizing on brand personalities in advertising: The influence of implicit self-theories of ad appeal effectiveness. Journal of Consumer Psychology, 22, 424-433. doi: 10.1016/j.jcps.2011.05.004.

[18] Yorkston, E. A., Nunes, J. C., \& Matta, S. (2010). The malleable brand: The role of implicit theories in brand extendibility. Journal of Marketing, 74, 80-93. doi: 10.1509/jmkg.74.1.80.

[19] Yeager, D. S. (2017). Dealing with social difficulty during adolescence: The role of implicit theories of personality. Child Development Perspectives, 11 (3), 196-201. doi: 10.1111/cdep.12234.

[20] Mathur, P., Jain, S. P., \& Maheswaran, D. (2012). Consumers' implicit theories about personality influence their brand personality judgments. Journal of Consumer Psychology, 22, 545-557. doi: 10.1016/j.jcps.2012.01.005.

[21] Critcher, C. R., Dunning D., \& Rom S. C. (2015). Causal trait theories: a new form of person knowledge that explains egocentric pattern projection. Journal of Personality and Social Psychology. Journal of Personality and Social Psychology, 108 (3), 400-416. doi: 10.1037/pspa0000019.

[22] Romero, C., Master, A., Paunesku, D., Dweck, C. S., \& Gross, J. J. (2014). Academic and emotional functioning in middle school: The role of implicit theories. Emotion, 14 (2), 227234. doi: $10.1037 / \mathrm{a} 0035490$.

[23] Xu, P., Xiong, J., \& Fan, J. Y. The Impulse process of language structure parts' speech flow. Journal of Applied Statistics and Management, 2013, 32 (4): 685-698. doi: 10.13860/j.cnki.slt j.2013.04.010.

[24] Hoyt, C. L., \& Burnette, J. L. (2013). Gender bias in leader evaluations: Merging implicit theories and role congruity perspectives. Personality and Social Psychology Bulletin, 39 (10), 1306-1319. doi: 10.1177/0146167213493643.
[25] Wendy, W. (2017). Habit in Personality and Social Psychology. Personality and Social Psychology Review, 21 (4), 389-403. doi: 10.1177/1088868317720362.

[26] Satchell, L., Hoskins, S., Corr, P., \& Moore, R. (2017). Ruminating on the nature of intelligence: Personality predicts implicit theories and educational persistence. Personality and Individual Differences. Personality and Individual Differences, 113, 109-114. doi: 10.1016/j.paid.2017.03.025.

[27] Kast, V. (2001). Abschied von der Opferrolle. Freiburg: Herder.

[28] Rutledge, E. L., Crouch, J. L., Valentiner, D. P., Davila, A. L., Milner, J. S., \& Skowronski, J. J. (2018). Are implicit personality theories associated with parental reactions to child transgressions? Personality and Individual Differences, 128, 113-121. doi: 10.1016/j.paid.2018.02.021.

[29] Goddard, M. J. (2018). Extending B. F. Skinner's selection by consequences to personality change, implicit theories of intelligence, skill learning, and language. Review of General Psychology, 22 (4), 421-426. doi: 10.1037/gpr0000168.

[30] Cripps, E., Wood, R. E., Beckmann, N., Lau, J., Beckmann, J. F., \& Cripps, S. A. (2016). Bayesian Analysis of Individual Level Personality Dynamics. Frontiers in Psychology, 7, 1065. doi: 10.3389/fpsyg.2016.01065.

[31] Steimer, A., \& Mata, A. (2016). Motivated implicit theories of personality: My weaknesses will go away, but my strengths are here to stay. Personality and Social Psychology Bulletin, 42 (4), 415-429. doi: 10.1177/0146167216629437.

[32] Sheketera, A. A., \& Bogomaz, S. A. (2015). Features of Formation of Implicit Theories and their Relation to Students' Intellectual and Personal Potential. Procedia-Social and Behavioral Sciences, 200, 372-376. doi: 10.1016/j.sbspro.2015.08.080.

[33] Liat, L., Ora, Nakash., \& Shai D. (2019). It takes two to self-disclose: Incremental theorists facilitate others' self-disclosure more than do entity theorists. Journal of Personality, 87 (6), 1264-1276. doi: 10.1111/jopy.12473.

[34] Friedman, R. A., Pinkley, R. L., Bottom, W. P., Liu, W., \& Gelfand, M. (2019). Implicit Theories of Negotiation: Developing a Measure of Agreement Fluidity. Negotiation and Conflict Management Research, 13 (2), 127-150. doi: $10.1111 / \mathrm{ncmr} .12166$.

[35] Jędrzejczyk, J., \& Zajenkowski, M. (2020). Who Believes in Nonlimited Willpower? In Search of Correlates of Implicit Theories of Self-Control. Psychological Reports, 123 (2), 281-299. doi: 10.1177/0033294118809936.

[36] Lee, Y. H., \& Yeager, D. S. (2020). Adolescents with an entity theory of personality are more vigilant to social status and use relational aggression to maintain social status. Social Development, 29 (1), 273-289. doi: 10.1111/sode.12393.

[37] Sutu, A., Serrano, S., Schultz, L. H., Jackson, J. J., \& Damian, R. I. (2020). Creating through deviancy or adjustment? The link between personality profile normativeness and creativity. European Journal of Personality, 33 (5), 565-588. doi: 10.1002/per.2215. 